\title{
Phase-Contrast MRI Indices can Reflect Intracranial Compliance Deterioration Induced by Intra-Abdominal/ Thoracic Hypertension
}

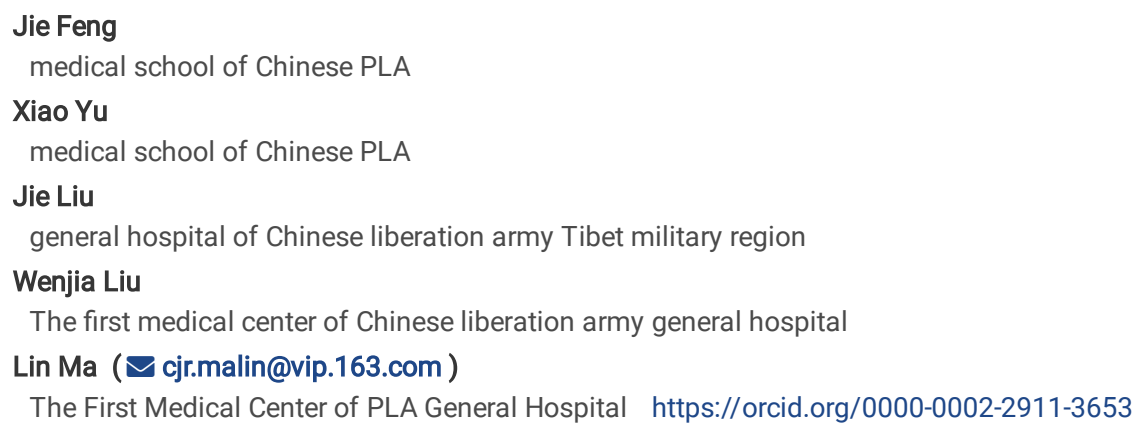




\section{Abstract}

\section{Background}

Identifying elevated intracranial pressure (ICP) and decreased intracranial compliance (ICC) is imperative for optimizing patient management in neurocritical care settings. Intra-abdominal hypertension (IAH) and intrathoracic hypertension (ITH) is common in trauma patients, which affects homeostasis of ICP/ICC. Knowledge of this effects is little and monitoring this effect is difficult. In the current study, we examined whether the indices generated from 2D cine phase contrast MRI (2D cine PC-MRI) could reflect ICC/ICP alterations induced by elevated IAH/ITH during VM.

\section{Methods}

A total of 50 healthy young volunteers participated in this study (male: female $=24: 26$ ), and took a 2D cine PC-MRI during normal breath and VM respectively. Cross-section area (CSA) of dominant IJV and ipsilateral ICA, the maximum blood flow $\left(F_{\text {max }}\right)$, minimum blood flow $\left(F_{\text {min }}\right)$, mean blood flow $(M B F)$, pulsatility index (PI), arteriovenous delay (AVD) and time to peak of arterial pulse (TTP) were gauged from images or calculated from the blood flow curves generated from 2D cine PC-MRI.

\section{Results}

During VM state, in comparison to NB, $C S A_{I J V}$ increased significantly $(p<0.0001)$, indicating an elevation of cerebral venous outflow resistance; $F_{\text {max } \_ \text {ICA, }}$ $F_{\text {max_IJV, }} F_{\text {mean_ICA }}$ and $F_{\text {mean_IJV }}$ decreased significantly $(p<0.0001, p<0.0001, p<0.001, p<0.0001$, respectively); PI_JCA and PI_JJV decreased significantly $(p<0.0001, p<0.0001)$; both absolute and normalized AVD decreased significantly $(p<0.0001, p<0.0001)$, while absolute and normalized TTP increased significantly $(p=0.0329, p=0.0376)$.

\section{Conclusions}

Indices generated from 2D cine PC-MRI, especially AVD and TTP, can reveal the ICC/ICP dynamics induced by elevated IAP/ITP. These indices have potential clinical application in ICC/ICP monitoring in patients who was speculated with an IAH or ITH.

\section{Introduction}

The homeostasis of intracranial pressure (ICP) is of utmost importance for maintaining normal brain function. The content of the closed cranial vault is composed by the brain, venous- and arterial blood, and the cerebrospinal fluid (CSF), all of which are virtually incompressible. Any expansion of one of these components must be compensated by a displacement of volume from one or more of the others ${ }^{[1]}$. This compensational capacity is defined as intracranial compliance (ICC) ${ }^{[2]}$. Once the compliance runs out, there will be an exponential rise in ICP ${ }^{[2]}$. Thus, monitoring ICC dynamics would get insight into the subsequent ICP dynamics.

However, ICP/ICC is not only influenced by intracranial contents, as ICP has been shown to have a complex relationship with both intra-abdominal pressure (IAP) and intrathoracic pressure (ITP). The ICP, IAP and ITP are closely interrelated in conditions of intra-abdominal hypertension (IAH), intrathoracic hypertension (ITH), abdominal compartment syndrome (ACS) and multicompartment syndrome (MCS), which were frequently encountered in patients with traumatic brain injury (TBI) and those complicating with multiple injury ${ }^{[3-5]}$. Impeded cerebral perfusion by intracranial hypertension (ICH) will lead to cerebral ischemia. Further fluid administration to support cerebral perfusion or increasing ventilatory support to treat acute lung injury will further increase ICP, which can create a cycle that ultimately produces or aggravates $\mathrm{MCS}^{[6]}$. When it cannot be managed by maximal medical means, brain ischemia is the single most important factor increasing morbidity and mortality after $\mathrm{TBI}^{[6]}$. Therefore, optimization of patients with TBI should involves treatment of intracranial disorders and other organ systems that was cognizant of possible central nervous system effects ${ }^{[7]}$. IAH is a continuum from asymptomatic elevation of IAP to an immediately life-threatening situation, where dynamic evolution in both directions is possible. Therefore, it is difficult to identify triggers for interventions that may lead to complications or have adverse effects ${ }^{[8]}$. To date, no indicators for predicting the influence of IAH/ITH on ICP have been reported. Timely detection of decreased ICC or raised ICP allows for early management, which reduces the risk of permanent brain damage, and improves patients outcome after brain injury ${ }^{[9]}$. However, direct monitoring ICC and ICP is difficult and risky, impeding it benefit for more patients. Several non-invasive methods had developed in last decades. Two-dimensional cine phase contrast MRI (2D cine PC-MRI) is one of these non-invasive methods. By gauging the parameters of cerebral hemodynamics and cerebrospinal fluid dynamics, the 2D cine PC-MRI can estimate ICP/ICC qualitatively or quantitatively.

The Valsalva maneuver (VM), a natural response during coughing, defecation, and lifting heavy loads, is defined as a forced exhalation against a closed glottis. The VM is commonly used to test cardiac functions or autonomic nervous system deficiencies ${ }^{[10]}$. Moreover, VM is also a well-established physiological model of ICH or IAH in basic and clinical research ${ }^{[11,12]}$. During VM state, increased IAP/ITP causes an increase in back pressure in the jugular veins (IJV), impeding venous blood drainage through IJV and leading to an increase of intracranial venous volume ${ }^{[13-15]}$. According to the Monroe-Kellie doctrine, a decrease of ICC or an elevation of ICP can be modeled ${ }^{[16,17]}$.

We conducted this study, aimed to investigate the effects of elevated IAP/ITP (modelled by VM) on ICC/ICP changes, and the potential indices that can be used in ICC/ICP monitoring in patients, using PC-MRI.

\section{Methods}


The protocol was approved by the Ethics Committee of the General Hospital of the Chinese People's Liberation Army (Registry NO. S2015-014-02), and conformed to standards set by the Declaration of Helsinki.

A group of healthy young subjects were recruited for this study. Participants were informed of the potential risks and experimental procedures, and informed written consent was obtained. All procedures and protocols were approved by the ethics committee of the General Hospital of PLA and performed in accordance with the Declaration of Helsinki. Participants abstained from alcohol, caffeine, and strenuous exercise for at least $24 \mathrm{~h}$ before the MRI scan.

\section{MRI Data Acquisition}

All MRI examinations were performed on a 3.0T scanner (GE Discovery MR 750, Waukesha, WI) using an 8-channel head coil. Maximum intensity projection (MIP) of 2D-PC-MRV and T2 weighted images were used as localizer (Figure1). Velocity (encoding) sensitization was set at $50 \mathrm{~cm} / \mathrm{s}$, at which the internal carotid arteries (ICA) and internal jugular vein (IJV) can be imaged simultaneously. The plane that was perpendicular to bilateral ICA and IJV, passing through the level of odontoid process root of the second cervical vertebra, were selected for 2D cine PC-MRI acquisition (Figure1). The MRI parameters of 2D cine PCMRI sequence were as follows: TR $=7.0 \mathrm{~ms}, T E=3.6 \mathrm{~ms}$, slice thickness $=4 \mathrm{~mm}$, trigger time $=19 \mathrm{~ms}$, acquisition matrix $=224 \times 224$, flip angle $=20^{\circ}$. Velocity (encoding) sensitization was set at 70 to $90 \mathrm{~cm} / \mathrm{s}$. Retrospective cardiac gating was selected, so that the 60 frames covered the entire cardiac circle (CC) were acquired. Each participant underwent the 2D cine PC-MRI sequence twice, once during normal breath (NB), and once during VM, using the same parameters and at the same plane. Acquisition time for once 2D cine PC-MRI was approximately $45 \mathrm{~s}$ and $38 \mathrm{~s}$ during NB and VM respectively, depending on the heart rate of individual. Total MRI scan was accomplished approximately in 10 mins. Before MRI scan, all participants practiced VM under the researcher's instructions. The sub-maximal VM (approximately $60 \%$ of one's maximal VM according to personal feeling) was adopted for 2D cine PC-MRI scan, for safety. Respiratory motion was monitored by placing bellows around the thoracoabdominal region, and PC-MRI scan started at the beginning of strain (phase $\mathbb{\text { a }}$ of VM ) manually (Figure1).

\section{Measurement and indices calculation}

All 2D cine PC-MRI data processing operations were performed with commercial workstations (GE, ADW 4.6) using Cardiac VX_1.1.0 software. Regions of interest (ROIs) was manually drawn around the boundary of the vessels of interest (bilateral ICA and IJV) on the amplitude map, referring to phase map when necessary, in the frame with maximum cross-sectional area (CSA), and the vessels were tracked automatically in all time frames. Blood flow was measured in ICA and IJV simultaneously. The blood flow curves of the CC were calculated by the 60 frames (Figure 2). Then, the curve of IJV were reversed. The maximum flow $\left(F_{\text {max }}, \mathrm{ml} / \mathrm{s}\right)$, minimum flow $\left(F_{\min }, \mathrm{ml} / \mathrm{s}\right)$ and mean blood flow $\left(F_{\text {mean }}, \mathrm{ml} / \mathrm{s}\right)$ and the CSA $\left(\mathrm{mm}^{2}\right)$ throughout the CC were generated against either the flow curve or image. According to the CSA of IJV during NB, the IJV with larger CSA and ipsilateral ICA were defined as the dominant side ${ }^{[18]}$. The arteriovenous delay (AVD) were measured as the time delay between the $F_{\max }$ of IJV $\left(F_{\max \_I J V}\right)$ and $F_{\max }$ of ipsilateral ICA $\left(F_{\max \_I C A}\right)$. The time to peak of bilateral ICA flow curve (TTP ICA $)$ was the time took of the arterial blood flow from $F_{\text {min_ICA }}$ to $F_{\text {max_ICA }}$. Both the absolute and normalized (divided by the time of CC, $R_{T T P \_I C A}$ $\mathrm{R}_{\mathrm{AVD}}$ ) TTP ICA and AVD were used for statistic calculation, to eliminate the influence of heart rate (figure 2). The pulsatility index (PI) were calculated according to previous reported method ${ }^{[19]}$, based on blood flow:

$\mathrm{PI}=\left(\mathrm{F}_{\text {max }}-\mathrm{F}_{\text {min }}\right) / \mathrm{F}_{\text {mean }}$.

\section{Statistics}

IBM SPSS Statistics for Windows, version 25. (Armonk, NY, USA: IBM Corp.) was used for Statistical calculation. Comparisons of values were performed with paired t-tests for normally distributed differences between VM and NB, and with nonparametric Wilcoxon's signed rank test otherwise. For all tests, the level of significance was set at $p<0.05$.

\section{Results}

\section{Demographic information}

Fifty-six participants were recruited, in whom fifty (male/female =24/26; age, $27.2 \pm 4$ years) participants completed the trial. The demographic information was detailed in Table1.

\section{Vessel Area}

In total 50 participants, 35 were right IJV dominant, and the other 15 were left dominant. Dominant side was used in succeeding analysis. During VM, CSA $\mathrm{IJV}$

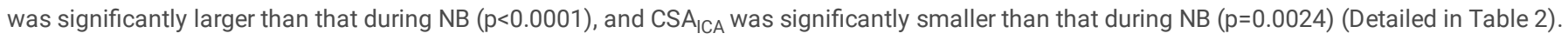

\section{Blood Flow and Pulsatility}

During VM, $F_{\text {max_ICA }}$ and $F_{\text {max_IJV }}$ decreased significantly $(p<0.0001, p<0.0001)$, $F_{\text {mean_ICA }}$ and $F_{\text {mean_IJV }}$ decreased significantly $(p<0.001$, $p<0.0001)$, while

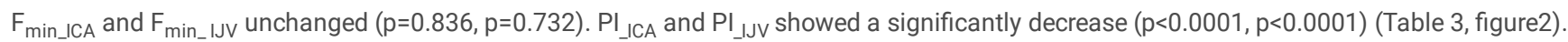

\section{Arteriovenous Delay and Time to Peak}

AVD and $R_{A V D}$ shortened significantly during VM ( $<<0.0001$, $\left.p<0.0001\right)$, while TTP and $R_{\text {TTP_ICA }}$ prolonged significantly $(p=0.0329, p=0.038)$. From the blood flow curves, the peak of flow curve of IJV shifted to left, and the wave of blood flow in ICA broadened and the peak shifted to right (Table 4, figure3). 


\section{Discussion}

\section{Key results}

The present work investigated the use of 2D cine PC-MRI as a means of assessment of ICC/ICP dynamic in young healthy subjects in a situation of elevated IAP/ITP modeled by VM. In this study, we demonstrate that elevated IAP/ITP causes ICC/ICP changes during VM, which can be revealed using 2D cine PC-MRI. Larger $\mathrm{CSA}_{\mathrm{IJV}}$ indicated an elevation of back pressure of IJV. Compared with baseline, smaller AVD indicates a decreased ICC or increased ICP, while larger TTP indicates a decreased ICC or increased ICP. These indices have a potential use in non-invasive ICC/ICP monitoring in patients with elevated IAP/ITP.

\section{Interpretation the results}

It had been universally recognized that the VM is a model of IAP and ITP elevation. In the present study, the dilation of IJV is and indicator of CVP elevation, which is caused by the increased IAP and ITP. Although most of the indices changed during VM, the PI was the candidate for measurement ICP in most previous studies. Despite AVD and TTP were reported only in very few studies, these two indices played a powerful role reflecting the VM induced ICC/ICP changes in the present study. Here, the interpretation of the changes of these indices will be discussed.

\section{Interpretation of the decreased PI}

PI describes the pulsatility of blood flow waveform. Evidence suggests that either increased ${ }^{[19]}$ or decreased ${ }^{[20]} \mathrm{PI}$ are harmful to the brain. During straining (VM phase $₫)$, central venous pressure (CVP) increased, cardiac output (CO) decreased and blood flow of middle cerebral artery dropped significantly ${ }^{[21]}$. Our result demonstrate the $F_{\text {max }}$ dropped more than $F_{\text {mean }}$, while the $F_{\text {min }}$ remained constant, so the PI decreased. Dropped $F_{\text {mean }}$ indicated dropped cerebral perfusion pressure (CPP), that is consistent with previous study. However, although PI is commonly considered an indicator of CPP as opposed to ICP, there exists a complex relationship between $\mathrm{PI}$ and multiple hemodynamic variables including CPP, arterial pressure pulse amplitude, cerebrovascular resistance (CVR), arterial compliance, and heart rate ${ }^{[22]}$. Under normal conditions, $\mathrm{PI}$ is predicted to increase linearly with ICP ${ }^{[23,24]}$. While in a recent study, ICP estimated using PI method $(\mathrm{ICP}=\mathrm{a} \times \mathrm{PI}+\mathrm{b})$ of five in eight individuals were reported a trend of decrement during VM state ${ }^{[25]}$. Their results are consistent with the present study. A recent study also reported that increased ICP attenuates the pulsatility of cerebral venous outflow ${ }^{[26]}$.

Theoretically, venous outflow is a passive component, the intracranial pulse wave is predominately determined by the arterial wave ${ }^{[1]}$. Under conditions of the cardiac insufficiency and CVP increased, which is prevalent in critical ill patient and also in VM, venous pressure influences the intracranial wave more ${ }^{[27,28]}$. During VM, the increased CVP impedes venous outflow, which in turn lead to an increment of cerebral blood volume and a "stiffer" brain. both the "stiffer" brain and the insufficiency cardiac function led to the CBF decrement and in particular the maximum blood flow. Thus, the pulsating component of the ICA and the IJV decreased.

\section{Interpretation of the shortened AVD}

Monroe-Kellie doctrine states that, the volumetric interplay between intracranial components (arterial blood, brain, venous blood and CSF) maintains ICP homeostasis ${ }^{[29]}$. In a cardiac circle, heart contraction induces a pulsatile artery blood entering the closed cranial cavity, which causes brain remolding and a transient perturbation of ICP homeostasis ${ }^{[30,31]}$. The arterial expansion must be compensated by venting CSF into the spinal canal and venous outflow ${ }^{[1,32]}$. A minimal time delay between arterial inflow and venous outflow from the cranial cavity has constantly been observed in previous studies ${ }^{[32-36]}$,which was measured as $\mathrm{AVD}^{[37]}$.

Pulse wave velocity (PWV) or the time the pulse wave takes to travel the length of the artery was used to reflecting the compliance of the arterial tree ${ }^{[38,39]}$. PWV has been considered the gold standard for measuring arterial stiffness ${ }^{[38,40,41]}$, higher PWV was independently associated with greater target organ damage ${ }^{[42]}$. Similarly, ICC can be estimated by measuring the PWV that traverses the intracranial space. In a certain distance, AVD, the time the pulse wave takes to travel from the arterial to the venous side of the cerebral circulation, is the reciprocal of PWV. AVD gauged from ICA to IJV at the skull base is a reflection of the compliance of the intracranial space, which includes arteries, subarachnoid space, brain parenchyma and veins. Smaller AVD have been reported in patients with normal pressure hydrocephalus $(\mathrm{NPH})^{[43]}$, late-onset idiopathic aqueductal stenosis (LIAS) ${ }^{[44]}$ and Multiple sclerosis (MS) ${ }^{[45]}$. What's more, larger AVD have been reported in patients with NPH after a CSF drainage than pre-drainage $\mathrm{e}^{[43]}$.

There were few studies devoted to AVD measuring can be referred. In a study, AVD measured at the level of intervertebral disc of cervical-2 to cervical-3 using the same method, a smaller AVD ( $72 \pm 24 \mathrm{~ms}$, representing $8 \pm 2 \%$ of the CC duration vs. 106 ) were reported in 18 ( 9 female, 9 female) healthy young volunteers ${ }^{[46]}$. In another study, a larger AVD (17\% $\pm 7 \%$ of the CC) in 19 (3 female, 16 female) healthy young volunteers were reported. This difference might be contributed to the different temporal resolution we used (32 frames per CC vs. 60 frames per CC we used). More accurate measure was expected by adopting a higher temporal resolution. In several other studies, AVD was measured as the time delay between the center of arterial pulse and the center of venous pulse, and the AVD was measured at much higher plane than the present study, so the results can't be compared directly ${ }^{[37,43]}$.

Under the VM state, forced expiration against a closed glottis increased IAP and ITP, damping IJV outflow and venting CSF upwards motion into the cranial cavity ${ }^{[47]}$, in turn, leading to an immediate stiffening of the brain and a rise of ICP (or a decrease of ICC) ${ }^{[48]}$. Shear waves propagate more quickly through a stiffer material[ ${ }^{[49]}$. Smaller AVD during VM than NB reflects the ICC decline during VM.

\section{Interpretation of the prolonged TTP}


A recent study using invasive monitoring methods simultaneously recorded ICP and CBF waveform in non-human primate, reported that a higher ICP led to a broadening and rightward shift of the ICP and CBF pulse wave ${ }^{[50]}$, although the strength of this effect differed between subjects. In patients with NPH underwent CSF drainage, the arterial pulse became thinner, and peaked earlier than pre-drainage ${ }^{[43]}$. These results are consistent with the prolonged TTP during VM reported in our work. The TTP reflects the resistance of blood flow. Elevated IAP/ITP caused a decreased ICC and increased ICP, and in turn, the increment resistance of arterial perfusion, this has been reported in both animal model of IAH ${ }^{[51]}$ and in man during VM ${ }^{[52]}$. In the present study, the smaller $\mathrm{CSA}_{\mathrm{ICA}}$ and decreased $\mathrm{F}_{\text {mean }}$ also implied a restrictive effect of sympathetic activity during VM, which also led to an increase of vascular resistance.

\section{Limitations}

The strength of our study is fundamentally limited by that VM can only partially model IAH/ITH. (1) VM elevates IAP/ITP for a relatively short time, while IAH/ITH usually rises for hours to even for days in clinical scenarios; (2) All the subjects enrolled in this work were normal, that the respiration and circulation is different from patients with multiple trauma, in whom IAH/ITH often occurs after excessive fluid therapy. Validation of these indices in clinical scenarios is needed. The second limitation is that mouth pressure, regarded as a surrogate for ITP, was not measured during VM. At a given increased ITP, diverse proportion of transmission to ICP was reported in previous studies ${ }^{[53]}$. Thus, the dynamic trends comparing to baselinerather than the absolute value of these indices are valuable when applicate this method ${ }^{[54]}$. The safety of a repeated MRI examination, the difficulty of intracranial monitoring and the emergence and development of portable MRI ${ }^{[55-57]}$, suggest an oncoming MRI monitoring.

\section{Conclusions}

Using 2D cine PC-MRI and modelled by VM, this study investigated the influence of elevated IAP/ITP on ICP/ICC. The results showed that the AVD between ICA and IJV, and time to peak of ICA pulse-wave have a potential role in monitoring the patients with IAH/ITH. The smaller AVD and larger TTP indicate a trend of ICC decrease and ICP rise.

\section{Declarations}

\section{Ethical Approval and Consent to participate}

The protocol was approved by the Ethics Committee of the General Hospital of the Chinese People's Liberation Army (Registry NO. S2015-014-02), and conformed to standards set by the Declaration of Helsinki. All of the participants were informed of the potential risks and experimental procedures, and informed written consent was obtained.

\section{Consent for publication}

Not applicable.

\section{Availability of supporting data}

Data are the property of the authors and can be obtained by contacting the Principal Investigator: Dr. Jie F; e-mail: 13920449779@163.com

\section{Competing interests}

The authors declare that they have no competing interests.

\section{Funding}

This study was partially funded by 3 grants awarded to Lin Ma (81741115, and 16CXZ014 and 16BJZ11).

\section{Authors' contributions}

$\mathrm{J} F$ and $\mathrm{X} Y$ performed data analysis and wrote the first draft of the manuscript. $L \mathrm{M}$ conceived the study, $\mathrm{J} F, \mathrm{X} Y, \mathrm{~W} L$ and $\mathrm{J} L$ contributed to data collection and analysis, and edited the manuscript.

\section{Acknowledgements}

The authors would like to thank all the participants.

\section{Authors' information}

Jie Feng, email: 13920449779@163.com;

Xiao Y u, email: yuxiao301neuromr@163.com;

Jie Liu, email: 915788574@qq.com;

Wenjia Liu, email: liuwj1025@163.com;

Lin Ma, email: cjr.malin@vip.163.com. 


\section{References}

1. GREITZ D, WIRESTAM R, FRANCK A, et al. Pulsatile brain movement and associated hydrodynamics studied by magnetic resonance phase imaging. The Monro-Kellie doctrine revisited [J]. Neuroradiology. 1992;34(5):370-80.

2. WILSON MH. Monro-Kellie 2.0: The dynamic vascular and venous pathophysiological components of intracranial pressure [J]. Journal of cerebral blood flow metabolism: official journal of the International Society of Cerebral Blood Flow Metabolism. 2016;36(8):1338-50.

3. DE LAET I, CITERIO G, MALBRAIN ML. The influence of intra-abdominal hypertension on the central nervous system: current insights and clinical recommendations, is it all in the head? [J]. Acta Clin Belg. 2007;62(Suppl 1):89-97.

4. KAMINE T H, ELMADHUN N Y, KASPER E M, et al. Abdominal insufflation for laparoscopy increases intracranial and intrathoracic pressure in human subjects [J]. Surgical endoscopy. 2016;30(9):4029-32.

5. KOUTSOUKOU A, KATSIARI M. ORFANOS S E, et al. Respiratory mechanics in brain injury: A review [J]. World journal of critical care medicine. 2016;5(1):65-73.

6. SCALEA T M, BOCHICCHIO G V, HABASHI N, et al. Increased intra-abdominal, intrathoracic, and intracranial pressure after severe brain injury: multiple compartment syndrome [J]. The Journal of trauma, 2007, 62(3): 647 - 56; discussion 56.

7. LAUERMAN M H, STEIN DM. Multicompartment management of patients with severe traumatic brain injury [J]. Curr Opin Anaesthesiol. 2014;27(2):21924.

8. DE LAET I E MALBRAINM, DE WAELE J J.. A Clinician's Guide to Management of Intra-abdominal Hypertension and Abdominal Compartment Syndrome in Critically III Patients [J]. Critical care. 2020;24(1):97.

9. MILLER JD, BECKER D P, WARD JD, et al. Significance of intracranial hypertension in severe head injury [J]. J Neurosurg. 1977;47(4):503-16.

10. FELKER G M, CUCULICH P S GHEORGHIADEM. The Valsalva maneuver: a bedside "biomarker" for heart failure [J]. Am J Med. 2006;119(2):117-22.

11. PERRY B G, MüNDEL T. COCHRANE D J, et al. The cerebrovascular response to graded Valsalva maneuvers while standing [J]. Physiological reports. 2014;2(2):e00233.

12. SPAHLINGER D M NEWCOMBL, ASHTON-MILLER J A, et al. Relationship between intra-abdominal pressure and vaginal wall movements during Valsalva in women with and without pelvic organ prolapse: technique development and early observations [J]. Int Urogynecol J. 2014;25(7):873-81.

13. WENDLING W, SADEL S, JIMENEZ D, et al. Cardiovascular and cerebrovascular effects of the applied Valsalva manoeuvre in anaesthetized neurosurgical patients [J]. Eur J Anaesthesiol. 1994;11(2):81-7.

14. YEOH T Y VENKATRAGHAVANL, FISHER JA, et al. Internal jugular vein blood flow in the upright position during external compression and increased central venous pressure: an ultrasound study in healthy volunteers [J]. Can J Anaesth. 2017;64(8):854-9.

15. NEVILLE L, EGAN RA. Frequency and amplitude of elevation of cerebrospinal fluid resting pressure by the Valsalva maneuver [J]. Canadian journal of ophthalmology Journal canadien d'ophtalmologie. 2005;40(6):775-7.

16. BRIMIOULLE S, MORAINE J J, NORRENBERG D, et al. Effects of positioning and exercise on intracranial pressure in a neurosurgical intensive care unit [J]. Physical therapy. 1997;77(12):1682-9.

17. PRABHAKAR H, BITHAL P K, SURI A, et al. Intracranial pressure changes during Valsalva manoeuvre in patients undergoing a neuroendoscopic procedure [J]. Minimally invasive neurosurgery: MIN. 2007;50(2):98-101.

18. CORMIO M, ROBERTSON C S. Ultrasound is a reliable method for determining jugular bulb dominance [J]. J Neurosurg Anesthesiol. 2001;13(3):250-4.

19. WEBB A J, SIMONI M. MAZZUCCO S, et al. Increased cerebral arterial pulsatility in patients with leukoaraiosis: arterial stiffness enhances transmission of aortic pulsatility [J]. Stroke. 2012;43(10):2631-6.

20. SHEHATA G A, ABDEL-KAREEM M I, YASSIN A E, et al. Subclinical cerebrovascular cognitive function, and mood changes in patients with systemic lupus erythematosus [J]. Open access rheumatology: research reviews. 2010;2:17-25.

21. POTT F, VAN LIESHOUT J J, IDE K, et al. Middle cerebral artery blood velocity during a valsalva maneuver in the standing position [J]. Journal of applied physiology (Bethesda, Md: 1985), 2000, 88(5): 1545-50.

22. DE RIVA N, BUDOHOSKI K P SMIELEWSKIP, et al. Transcranial Doppler pulsatility index: what it is and what it isn't [J]. Neurocritical care. 2012;17(1):5866.

23. CANAC N, JALALEDDINI K, THORPE S G, et al. Review: pathophysiology of intracranial hypertension and noninvasive intracranial pressure monitoring [J]. Fluids Barriers CNS. 2020;17(1):40.

24. BELLNER J, ROMNER B, REINSTRUP P, et al. Transcranial Doppler sonography pulsatility index (PI) reflects intracranial pressure (ICP) [J]. Surgical neurology. 2004;62(1):45-51. discussion.

25. LEE KJ, PARK C, OH J, et al. Non-invasive detection of intracranial hypertension using a simplified intracranial hemo- and hydro-dynamics model [J]. Biomedical engineering online, 2015, 14(51.

26. UNNERBäCK M, OTTESEN J T REINSTRUPP. Increased Intracranial Pressure Attenuates the Pulsating Component of Cerebral Venous Outflow [J]. Neurocritical care. 2019;31(2):273-9.

27. DE LAET I, CITERIO G, MALBRAIN ML. The influence of intraabdominal hypertension on the central nervous system: current insights and clinical recommendations, is it all in the head? [J]. Acta Clin Belg. 2007;62(Suppl 1):89-97.

28. HAMER J, ALBERTI E. HOYER S, et al. Influence of systemic and cerebral vascular factors on the cerebrospinal fluid pulse waves [J]. J Neurosurg. 1977;46(1):36-45. 
29. WILSON MH. Monro-Kellie 2.0: The dynamic vascular and venous pathophysiological components of intracranial pressure [J]. Journal of Cerebral Blood Flow Metabolism. 2016;36(8):1338-50.

30. BHADELIA RA, BOGDAN A R, WOLPERT SM. Cerebrospinal fluid flow waveforms: effect of altered cranial venous outflow. A phase-contrast MR flow imaging study [J]. Neuroradiology. 1998;40(5):283-92.

31. ADAMS A L, KUIJF H J, VIERGEVER M A, et al. Quantifying cardiac-induced brain tissue expansion using DENSE [J]. NMR Biomed. 2019;32(2):e4050.

32. BATEMAN GA. Pulse-wave encephalopathy: a comparative study of the hydrodynamics of leukoaraiosis and normal-pressure hydrocephalus [J]. Neuroradiology. 2002;44(9):740-8.

33. UNNERBäCK M, OTTESEN J T, REINSTRUP P. ICP curve morphology and intracranial flow-volume changes: a simultaneous ICP and cine phase contrast MRI study in humans [J]. Acta Neurochir. 2018;160(2):219-24.

34. ALPERIN N J, LEE S H, LOTH F, et al. MR-Intracranial pressure (ICP): a method to measure intracranial elastance and pressure noninvasively by means of MR imaging: baboon and human study [J]. Radiology. 2000;217(3):877-85.

35. UNNERBäCK M, OTTESEN J T REINSTRUPP. Validation of a mathematical model for understanding intracranial pressure curve morphology [J]. J Clin Monit Comput. 2020;34(3):469-81.

36. WAGSHUL M E, CHEN J J, EGNOR M R, et al. Amplitude and phase of cerebrospinal fluid pulsations: experimental studies and review of the literature [J]. J Neurosurg. 2006;104(5):810-9.

37. BATEMAN G A, LECHNER-SCOTT J, LEA R A.. A comparison between the pathophysiology of multiple sclerosis and normal pressure hydrocephalus: is pulse wave encephalopathy a component of MS? [J]. Fluids Barriers CNS. 2016;13(1):18.

38. YAMASHINA A, TOMIYAMA H, ARAI T, et al. Brachial-ankle pulse wave velocity as a marker of atherosclerotic vascular damage and cardiovascular risk [J]. Hypertension research: official journal of the Japanese Society of Hypertension. 2003;26(8):615-22.

39. DEMIR A, ÖZTüRK Ş, EKMEKçl AH, et al. Decrease in Pulse Wave Velocity is Associated with Clinical Improvement in Patients with Ischemic Stroke [J]. Journal of stroke cerebrovascular diseases: the official journal of National Stroke Association. 2020;29(11):105206.

40. WILLIAMS B, MANCIA G, SPIERING W, et al. 2018 Practice Guidelines for the management of arterial hypertension of the European Society of Hypertension and the European Society of Cardiology: ESH/ESC Task Force for the Management of Arterial Hypertension [J]. Journal of hypertension. 2018;36(12):2284-309.

41. FU X, LI X. XIONG L, et al. Cerebral Arterial Stiffness as A New Marker of Early Stage Atherosclerosis of The Cerebral Large Artery in Acute Stroke [J]. J Atheroscler Thromb. 2019;26(9):783-91.

42. COUTINHO T, TURNER S T, KULLO I J. Aortic pulse wave velocity is associated with measures of subclinical target organ damage [J]. JACC Cardiovascular imaging. 2011;4(7):754-61.

43. BATEMAN G A. Vascular compliance in normal pressure hydrocephalus [J]. AJNR American journal of neuroradiology. 2000;21(9):1574-85.

44. BATEMAN G A. Magnetic resonance imaging quantification of compliance and collateral flow in late-onset idiopathic aqueductal stenosis: venous pathophysiology revisited [J]. J Neurosurg. 2007;107(5):951-8.

45. KOCHKOROV A, GUGLETA K, KAVROULAKI D, et al. Rigidity of retinal vessels in patients with multiple sclerosis [J]. Klin Monatsbl Augenheilkd. 2009;226(4):276-9.

46. STOQUART-ELSANKARI S, LEHMANN P, VILLETTE A, et al. A phase-contrast MRI study of physiologic cerebral venous flow [J]. Journal of cerebral blood flow metabolism: official journal of the International Society of Cerebral Blood Flow Metabolism. 2009;29(6):1208-15.

47. WOSTYN P, AUDENAERT K, DE DEYN P P. The Valsalva maneuver and Alzheimer's disease: is there a link? [J]. Curr Alzheimer Res. 2009;6(1):59-68.

48. TZSCHäTZSCH H, KREFT B, SCHRANK F, et al. In vivo time-harmonic ultrasound elastography of the human brain detects acute cerebral stiffness changes induced by intracranial pressure variations [J]. Sci Rep. 2018;8(1):17888.

49. MURPHY M C, HUSTON J. 3RD, EHMAN R L. MR elastography of the brain and its application in neurological diseases [J]. Neurolmage, 2019, 187(176 83.

50. RUESCH A, YANG J. SCHMITT S, et al. Estimating intracranial pressure using pulsatile cerebral blood flow measured with diffuse correlation spectroscopy [J]. Biomedical optics express. 2020;11(3):1462-76.

51. KARAKOULAS K A, VASILAKOS D. GROSOMANIDIS V, et al. Effects of pneumoperitoneum and LPS-induced endotoxemia on cerebral perfusion pressure in pigs [J]. J Neurosurg Anesthesiol. 2006;18(3):194-9.

52. ABIDI S, NILI M, SERNA S, et al. Influence of sex, menstrual cycle, and oral contraceptives on cerebrovascular resistance and cardiorespiratory function during Valsalva or standing [J]. Journal of applied physiology (Bethesda, Md: 1985), 2017, 123(2): 375 - 86.

53. $\mathrm{CHEN} \mathrm{H,} \mathrm{CHEN} \mathrm{K,} \mathrm{XU} \mathrm{JQ,} \mathrm{et} \mathrm{al.} \mathrm{Intracranial} \mathrm{pressure} \mathrm{responsiveness} \mathrm{to} \mathrm{positive} \mathrm{end-expiratory} \mathrm{pressure} \mathrm{is} \mathrm{influenced} \mathrm{by} \mathrm{chest} \mathrm{wall} \mathrm{elastance:} \mathrm{a}$ physiological study in patients with aneurysmal subarachnoid hemorrhage [J]. BMC Neurol. 2018;18(1):124.

54. WAKERLEY B R SHARMAVK. Transcranial Doppler derived pulsatility index in the assessment of intracranial pressure: the trend is your friend [J]. Neurosurgery. 2013;72(2):E319-20.

55. COOLEY C Z, MCDANIEL P C, STOCKMANN JP, et al. A portable scanner for magnetic resonance imaging of the brain [J]. Nature biomedical engineering, 2020.

56. SHETH K N, MAZUREK M H, YUEN M M, et al. Assessment of Brain Injury Using Portable, Low-Field Magnetic Resonance Imaging at the Bedside of Critically III Patients [J]. JAMA Neurol, 2020.

57. WALD L L, MCDANIEL P C, WITZEL T, et al. Low-cost and portable MRI [J]. Journal of magnetic resonance imaging: JMRI. 2020;52(3):686-96. 


\section{Tables}

\begin{tabular}{|ll|}
\hline \multicolumn{2}{|l|}{ TABLE 1 Demographic information } \\
\hline Age (year) & $27.2(4)$ \\
\hline Gender (Male: Female) & $24: 26$ \\
\hline BMI $\left(\mathrm{kg} / \mathrm{m}^{2}\right)$ & $20.618(3)$ \\
\hline SBP $(\mathrm{kpa})$ & $114.18(10)$ \\
DBP $(\mathrm{kpa})$ & $75.52(11)$ \\
\hline Dominant IJV (Left: Right) & Left: Right=15:35 \\
\hline
\end{tabular}

\begin{tabular}{|lll|}
\hline \multicolumn{3}{|c|}{ TABLE 2 Comparation of cross-sectional area during NB and VM } \\
\hline $\mathrm{CSA}$ & $\mathrm{CSA}_{\text {IJA }}\left(\mathrm{mm}^{2}\right)$ \\
\hline $\mathrm{NB}$ & 50 & 50 \\
\hline $\mathrm{VM}$ & $18.117(4.188)$ & $64.157(21.162)$ \\
$\mathrm{p}$ & 0.0024 & $79.948(23.992)$ \\
\hline
\end{tabular}

\begin{tabular}{|c|c|c|c|c|c|c|c|c|}
\hline & $\begin{array}{l}F_{\max \_I C A} \\
(\mathrm{ml} / \mathrm{s})\end{array}$ & $\mathrm{F}_{\max \_I J V}(\mathrm{ml} / \mathrm{s})$ & $\mathrm{F}_{\min \_I C A}(\mathrm{ml} / \mathrm{s})$ & $\mathrm{F}_{\mathrm{min} \_I J V}(\mathrm{ml} / \mathrm{s})$ & $\begin{array}{l}F_{\text {mean_ICA }} \\
(\mathrm{ml} / \mathrm{s})\end{array}$ & $\mathrm{F}_{\text {mean_IJV }}(\mathrm{ml} / \mathrm{s})$ & PI_ICA & PI_IJV \\
\hline$n$ & 50 & 50 & 50 & 50 & 50 & 50 & 50 & 50 \\
\hline NB & $6.212(1.148)$ & $9.051(7.23,10.78)$ & $3.497(3.081,3.952)$ & $5.349(3.972,6.142)$ & $4.70(0.78)$ & $7.00(5.73,8.796)$ & $0.59(0.51,0.66)$ & $0.48(0.35,0.67)$ \\
\hline VM & $5.473(1.139)$ & $6.709(5.35,7.28)$ & $3.49(3.10,4.21)$ & $5.02(3.95,5.78)$ & $4.27(0.94)$ & $5.68(4.47,6.45)$ & $0.44(0.36,0.55)$ & $\begin{array}{l}0.39 \\
(0.20,0.37)\end{array}$ \\
\hline $\mathrm{p}$ & $<0.0001$ & $<0.0001$ & 0.836 & 0.732 & $<0.001$ & $<0.0001$ & $<0.0001$ & $<0.0001$ \\
\hline
\end{tabular}

\begin{tabular}{|lllll|}
\hline \multicolumn{5}{|c|}{ TABLE 4 Comparation of AVD and TTP _ICA during NB and VM } \\
\hline & AVD (ms) & TTP ICA $_{\text {ICs }}(\mathrm{ms}$ & $\mathrm{R}_{\text {TTP_ICA }}$ & $\mathrm{R}_{\text {AVD }}$ \\
\hline $\mathrm{N}$ & 50 & 50 & 50 & 50 \\
\hline NB & $107(24.00,299.00)$ & $211.5(190.0,226.0)$ & $0.257(0.063)$ & $0.138(0.088,0.207)$ \\
\hline VM & $25(0.00,200.00)$ & $234.0(179.0,266.0)$ & $0.280(0.095)$ & $0.031(0.011,0.061)$ \\
\hline P & $<0.0001$ & 0.0329 & 0.0376 & $<0.0001$ \\
\hline
\end{tabular}

\section{Figures}



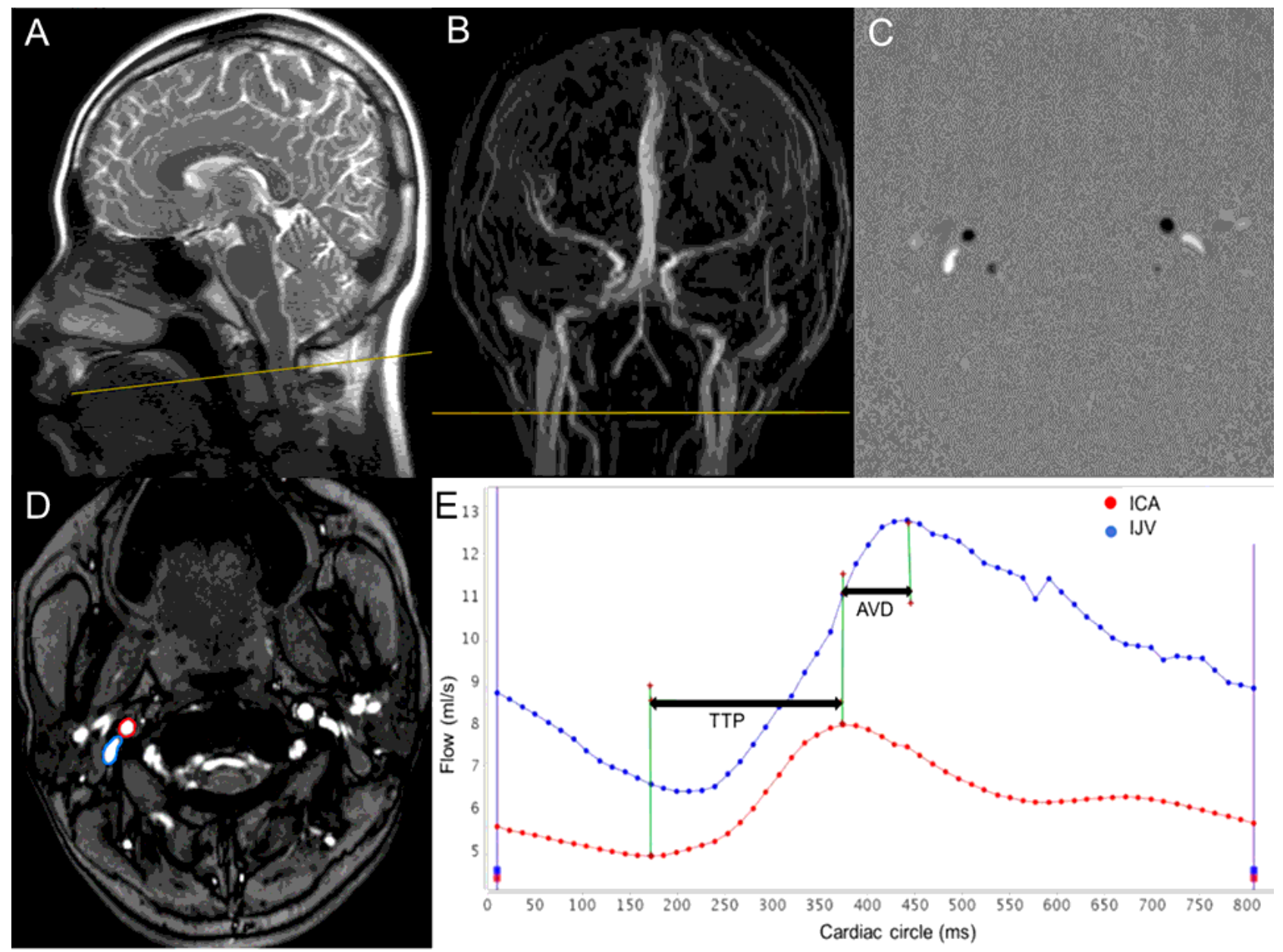

Figure 1

Schematic diagram for 2D cine PC-MRI scan localizing and indices gauging. T2 weighted image (A) and MIP of 2D-PC-MRV (B) are used as localizer. The yellow line represents the plane selected for 2D cine PC-MRI acquisition. The phase (C) and magnitude (D) images are acquired for indices measurement and calculation. The AVD is gauged as the time delay between the blood flow pulse-wave peaks of ICA (red curve) and IJV (blue curve); the TTPICA is gauged as the time took from Fmin_ICA to Fmax_ICA (E). 

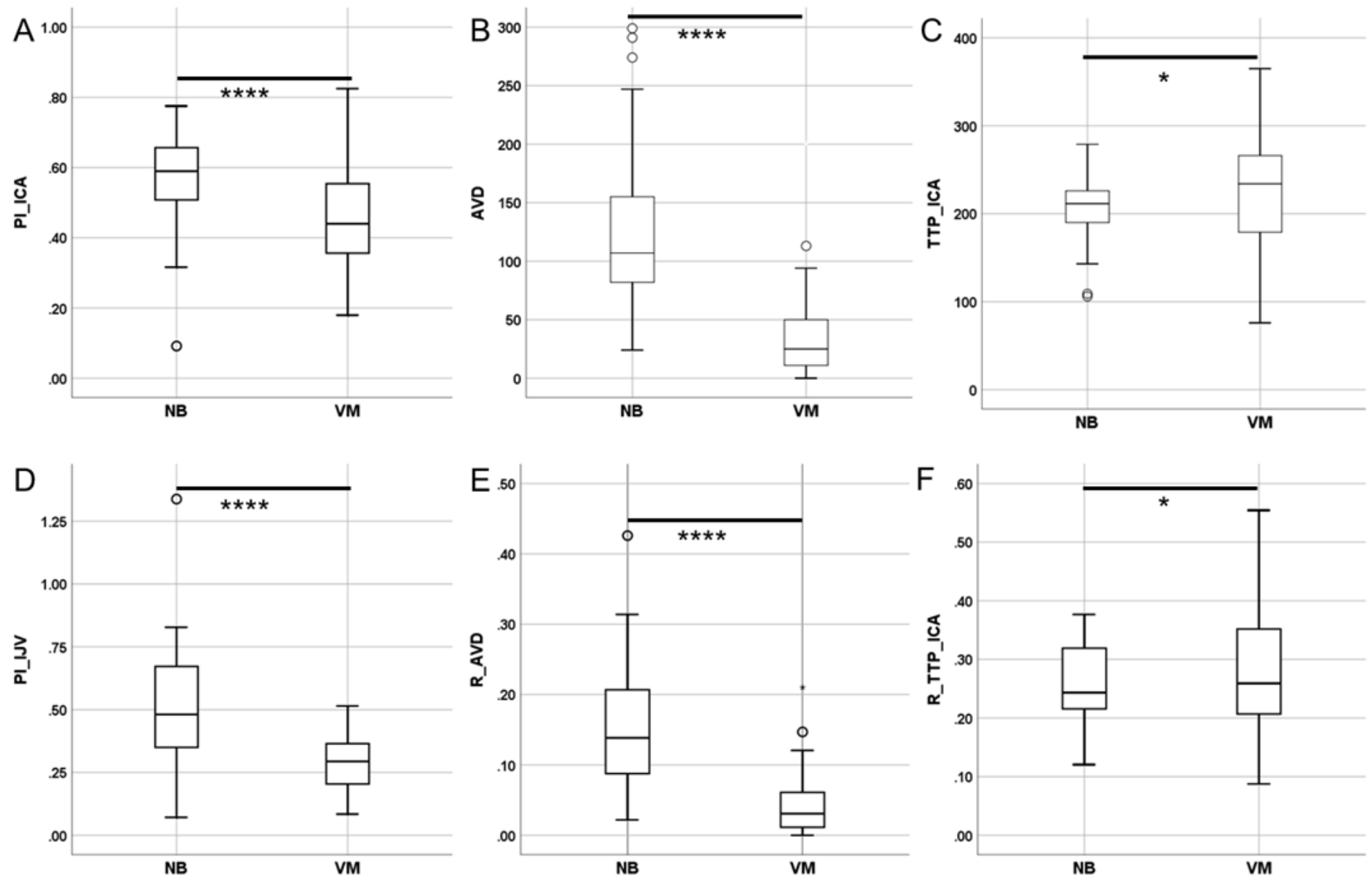

Figure 2

Comparation of indices generated during NB and VM. During VM, the PI_ICA and PI_IJV decreased, AVD and RAVD decreased and the TTP_ICA increased significantly. ${ }^{* \star * \star}, p<0.0001 ; * p<0.05$.

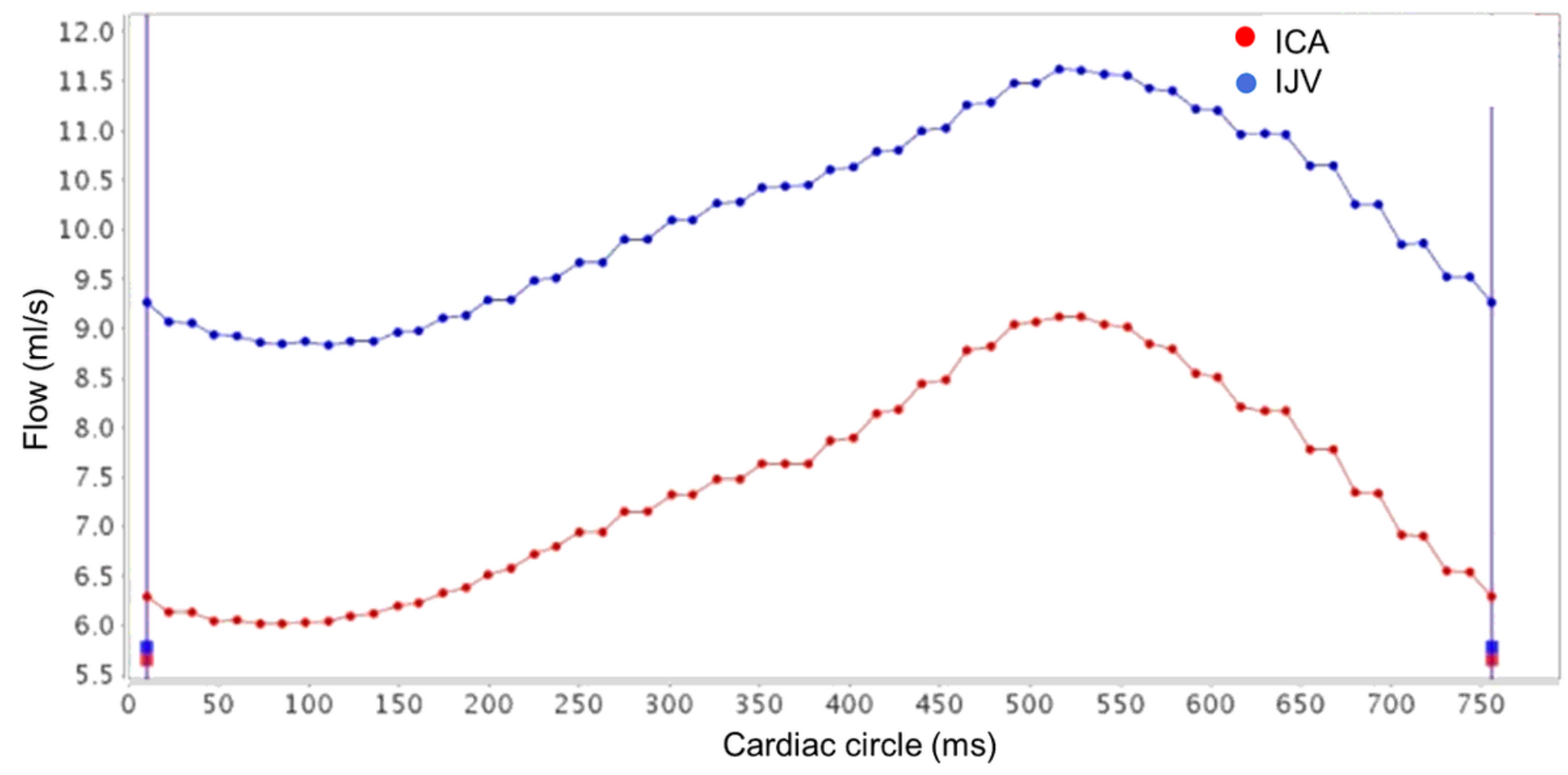

Figure 3

Page 10/11 
Pulse-wave curve of the same subject with FIGURE1 during VM. The AVD is shortened visibly, and the pulse-wave of ICA broadened, with a prolonged TTP.

Page $11 / 11$ 